\title{
The potential of peer support to extend the reach of digital health
}

\section{CURRENT STATUS: UNDER REVIEW}

BMC Health Services Research $\triangle$ BMC Series

Veronica Nanton

University of Warwick Warwick Medical School

V.Nanton@warwick.ac.ukCorresponding Author

ORCiD: https://orcid.org/0000-0002-9553-822X

Julia Roscoe

University of Warwick Warwick Medical School

Rebecca Appleton

University of Warwick Warwick Medical School

Amy Clarke

London Metropolitan University

Jeremy Dale

University of Warwick Warwick Medical School

\section{DOI:}

10.21203/rs.3.rs-21189/v1

\section{SUBJECT AREAS}

Health Economics \& Outcomes Research Health Policy

KEYWORDS

digital health; peer support; online intervention, access 
Abstract

Background Peer support groups have proliferated since the 1960s, providing safe, informal environments where peers can share experiences and information. A common model for the group is for those who have progressed further along a care pathway or in dealing with a particular medical condition or psycho-social problem, to encourage those at an earlier stage of recovery. Online support groups now co-exist with face to face models, providing a complementary or alternative resource for those with digital access and competence. As the paradigm of health care has moved towards the incorporation of health promotion, patient empowerment and self-management, peer support has extended to include more focussed activities. In particular peer support is included in a range of behaviour change interventions to promote engagement and adherence. Increasingly these interventions are delivered online. While this aims to extend their reach, it leaves those without digital access disadvantaged in terms of the ability to make use of online health resources.

Main text Though peer support has been used to maintain adherence to online programmes, its potential in assisting with access and thus widening participation has remained unknown. We successfully piloted the use of a paid peer supporter to help men without experience of IT to take part in an online intervention involving a prostate specific holistic needs assessment. Lessons were learnt from this innovation in relation to training needs and support for the supporter and around data security, confidentiality and safeguarding. Alternative models of voluntary peer support maybe appropriate, particularly in the implementation phase of an intervention and require exploration. Additionally a specific framework for best practice in relation to Digital Health interventions is needed to guide future development of the role.

Conclusion Health services are predicted to increasingly rely on digital technology over the next decade. Research into the impact of these seek to include participants representative of the entire population. Efforts must be made to include those who are currently underrepresented in research such as the elderly and other disadvantaged groups. Innovative research designs involving peer support in a research project may be valuable in addressing the current barriers to participation. Background 


\section{The development of peer support}

The origin of peer support has been traced back to a psychiatric hospital in late $18^{\text {th }}$ century France where the hospital governor recognised the benefit of employing former patients as staff. ${ }^{1}$ Little documentation of further development appears until the mid-1960s, when the support group, much as it is known today is first described as a therapeutic resource. ${ }^{2}$

Since the 1960s, condition or problem-based support groups have proliferated and provide safe, informal environments where peers can share experiences and information. Conceptual as well as applied aspects of the role have attracted academic interest since the $1970 \mathrm{~s}^{3} \mathrm{~A}$ recent exploration of peer support broadly defines its purpose "to encompass the provision of emotional and informational assistance by a created social network member who possesses experiential knowledge of a specific behaviour or stressor and similar characteristics as the target population."4

Support groups or associations are established in response to a perceived need by individuals experiencing a particular issue or are initiated by partners, friends or clinicians. A common model for the peer support group is for those who have progressed further, in terms of a care pathway or in dealing with a particular medical condition or psycho- social problem such as gambling or alcohol addiction, to encourage those at an earlier stage of recovery. Online support groups originating in the 1980s now co-exist with face to face models, so providing a complementary or alternative resource for those with digital access and competence. ${ }^{5}$

As the paradigm of health care has shifted from a paternalistic medical model of treatment to one incorporating health promotion, patient empowerment and self-management, peer support has developed and extended to include more focussed activities. ${ }^{1,6}$ Among these, peer support has been incorporated into the design of a range of behaviour change interventions. ${ }^{7,8}$ In the main these involve some form of lifestyle reorientation, with the goal of improving health. The peer supporter, with similar health-related experience, provides the opportunity for vicarious learning and modelling and is able to encourage and motivate the participant by helping to maintain engagement with the 
programme and improve long-term compliance. With the general expansion of digital health, these interventions, both one to one and group based, are moving to online delivery systems that potentially extends their reach and reduce costs to health services and to participants. Reviews of the effectiveness of the incorporation of peer support into behavioural interventions, both face to face and online, have been limited by heterogeneity of study designs. ${ }^{9,10,11,12}$ However in the areas of mental health, lifestyle and cardiovascular risk, a positive impact in specific domains including hope, sense of empowerment, quality of life, dietary behaviour and systolic blood pressure has been demonstrated. ${ }^{9,10,11}$

Main Text

\section{Digital health and peer support}

Digital health technologies offer limitless possibilities for improvements in patient care and since 2012 have gained a central place in United Kingdom (UK) national health policy. ${ }^{13}$ However, at present their reach is restricted to those able and willing to access and use information technology (IT). ${ }^{14} \mathrm{~A}$ variety of factors such as lack of IT literacy among older people, language related barriers and physical disabilities exclude sections of the population. As access to digital systems widens, it is anticipated that in time this disparity will diminish. While this may occur, it currently leaves those without access or ability to use an internet-enabled device, at a disadvantage in terms of what is on offer to help improve their health. ${ }^{15}$

Local projects and national programmes have aimed to improve digital access and literacy through voluntary initiatives for example the Digital Champion Programme lead by Age UK. ${ }^{16}$ More specifically focussed peer support in the digital domain has largely remained limited to encouraging compliance with online programmes. ${ }^{17,}$ 18, 19 Potential benefit may be gained however through the involvement of peers in enabling access to and participation in a range of digital health innovations such as online platforms and apps that provide information, help with decision making, or aid self-management and self-monitoring.

\section{Peer support in a digital health intervention}


To address the issue of access to digital health among older people and other underrepresented groups, we have been piloting a support role for peers that makes use of their skills, experience and empathy within the context of a research study. In designing our primary care-based feasibility study of an online cancer specific holistic needs assessment (csHNA) in prostate cancer (Integrated Care in

Prostate Cancer, ICARE-P) $20,21,22$ we were conscious of the need to encourage older men to take part and use the online system. To meet this need we developed the concept of an ITmate: a peer supporter with personal experience of prostate cancer who had sufficient confidence in using IT to allow him to assist others in taking part in the intervention. Set in a large conurbation in the West Midlands in the UK, the involvement of the ITmate proved invaluable in recruiting and engaging men in their mid-seventies and eighties.

The csHNA allows men to self-assess a range of physical and psychosocial concerns that commonly occur in association with prostate cancer. In planning the study, we had anticipated that participants would vary in their approach to the online system and that not all would require the same level of assistance. We envisaged that the ITmate would initially demonstrate the csHNA and that men would become increasingly independent users. However, in all instances he was asked to return to help participants undertake subsequent assessments. This may be un-surprising given the age and the degree of social isolation of the majority of participating men. The time lag between assessment time points (generally over 3 months) also limited the potential for observational learning that would enable men to navigate the system independently an important learning point for the development of comparable programmes.

For the ITmate himself, involvement in the study was demanding due to technical and logistical issues (e.g. arranging and attending study appointments at the required times), but enjoyable and rewarding to the extent that he continues to be involved in our programme of research.

\section{Challenges and lessons}

Initial challenges involved developing a role description that clearly defined its scope and limits. Subsequently, it was important to work with an established charity that already had an ongoing volunteer programme to help with advertising, screening and recruitment. As well as providing access 
to a wide range of potential candidates, this offered valuable safeguards to all involved.

Involving a peer supporter in a research study, particularly one in which participants are asked to disclose sensitive information, necessitate police disclosure and barring (DBS) checks are undertaken. Attention to issues of confidentiality and data security during the supporter training are also essential. A half-day session delivered by the research team addressed these issues as well as preparing the ITmate to introduce the csHNA to participants.

Valuable lessons for research and implementation were learnt during the study: a peer supporter involved in promoting participation in an online intervention must be confident in dealing with any problems that arise. Potentially, these may range from participant distress through to technical difficulties. Telephone access to a member of the project team for guidance and support during visits is critical. As well as a clear definition of the scope and limits of the role, peer supporters require guidance in the event of encountering a concerning situation such as a participant not answering the door when a home visit has been arranged, or when worrying information is disclosed. A lone worker policy is needed to ensure peer supporter safety. In addition, appropriate personal and vehicle insurance should be arranged during set up.

\section{Peer support: voluntary or paid}

Peer support has its roots in voluntarism and many organisations continue to rely on the large reserve of good will and experience of volunteers for its provision. With the development of peer roles that are more complex and demanding in terms of time commitment, training requirements and level of responsibility, professionalisation has become increasingly apparent.

In the UK, paid peer supporters typically earn between $£ 10$ - $£ 12$ per hour plus travelling expenses. ${ }^{23}$ Our ITmate was paid $£ 10$ per visit and travel costs were reimbursed. The average hourly rate in the United States of America for a 'specialist' peer supporter of $\$ 13.45$ is similar. ${ }^{24}$ National Health Service policy however, is to encourage and capture the enthusiasm of the large body of potential volunteers and to extend their role particularly with regard to supporting those with

long term conditions. ${ }^{25}$ Peer volunteers are frequently motivated by the desire to 'give something 
back'. ${ }^{26}$ Moreover, benefits of volunteering to the volunteer have been identified in a range of settings. ${ }^{27}$ Studies of the health of volunteer peer supporters who assist others with long term physical and mental conditions, have shown benefits in symptom reduction and improvements in aspects of quality of life. ${ }^{28}$ In addition, a high proportion of volunteers are retired and financial reward may not be a priority or may even incur a tax liability.

In terms of broadening digital access, various models of peer support are possible and require exploration. For example, as part of another current digital intervention project ${ }^{29}$ led by a member of our study team, peers with varying levels of IT experience have been recruited via a local support group overseen by a national umbrella organisation. The group members are involved on a voluntary basis in introducing potential users to an online platform to support informal carers.

The voluntary model appears more sustainable in terms of cost, particularly when individuals require ongoing assistance. It may be that paid peer support is most valuable in the intervention phase of a research study where there are likely to be additional requirements such as record keeping and attending study meetings. Volunteer-based peer support schemes may be best undertaken in the phase of wider implementation. Research is needed to clarify costs and benefits of both approaches in different contexts.

\section{A framework for best practice}

Whatever the particular model, there is a need for a framework for best practice for digital health interventions that involve peers. Codes of practice for guiding volunteer activity already exist. ${ }^{30}$ Similarly, safeguards are essential in the context of involvement in intervention delivery to protect both the peer and the participant. The need to establish some guiding principles has recently been identified by a group of international experts and in 2018 led to the publication of a consensus statement. ${ }^{2}$ This statement included a charter of overarching principles as well as allowing for cultural differences and health care contexts. While these are specific to peer support in the field of mental health, many of the principles laid out may have wider application and provide a framework on which more detailed and relevant guidelines may be developed. There is a need for a standard based 
protocol that relates specifically to digital technology.

\section{Conclusion}

\section{Peer support in digital health: research and implementation}

The future of healthcare is projected to rely increasingly on the use of digital technology at the point

of care as well as in terms of information management. ${ }^{31}$ Older people as well as disadvantaged minority groups are under-represented both in the use of health related technology and in digital intervention studies. ${ }^{15,32}$ We are currently extending our csHNA to cover the needs of patients with other cancers and we will incorporate a peer supporter role in the design of future studies based on the extended version of the csHNA. Research on digital health interventions must include older people and other digitally excluded groups if it is to be relevant and broadly applicable. Researchers must use imaginative ways of attracting their interest and creating and sustaining engagement. Health care has evolved in mode of delivery as well as content with the introduction and advance of digital technology. Through innovative research designs, models of peer support and roles of peer supporters can be developed and tested to ensure that the impact of technology has the widest possible reach and benefit across the population.

Abbreviations

UK United Kingdom

IT Information Technology

csHNA Cancer specific Holistic Needs Assessment

ICARE-P Integrated Care in Prostate Cancer

DBS Disclosure and Barring

NHS National Health Service

\section{Declarations}

\section{Ethics approval and consent to participate}

This study was approved by the East Midlands - Nottingham 2 Research Ethics Committee (REC reference: 15/EM/0534). Written consent to participate was obtained from all participants.

\section{Consent for publication}

Not applicable 


\section{Availability of data and materials}

Not applicable

\section{Competing interests}

The authors declare they have no competing interests

\section{Funding}

This paper presents independent research funded by the National Institute for Health Research (NIHR) under its Research for Patient Benefit (RfPB) Programme (Grant Reference Number PB-PG -021433092). The views expressed are those of the author(s) and not necessarily those of the NHS, the NIHR or the Department of Health. The funder played no role in the conduct of the research or in interpretation of findings.

\section{Authors' contributions}

VN wrote the first draft, JR, RA, AC and JD critically commented on and amended each further draft. All authors give final approval for this version to be published and agree to be held accountable for all aspects of the work.

\section{Acknowledgements}

We would like to thank our ITmate for his contribution to our research.

\section{References}

1. Tang P. A Brief History of Peer Support. 2013; Available from http://peersforprogress.org/pfp_blog/a-brief-history-of-peer-support-origins/ Accessed $16 / 10 / 19$

2. Stratford AC, Halpin M, Phillips K, Skerritt F, Beales A, Cheng V, Hammond M, O'Hagan M, Loreto C, Tiengtom K, Kobe B. The growth of peer support: an international charter. Journal of Mental Health. 2017 Jun 22:1-6.

3. Embuldeniya G, Veinot P, Bell E, Bell M, Nyhof-Young J, Sale JE, Britten N. The experience and impact of chronic disease peer support interventions: A qualitative synthesis. Patient education and counseling. 2013 Jul 1;92(1):3-12. 
4. Dennis CL. Peer support within a health care context: a concept analysis.

International journal of nursing studies. 2003 Mar 1;40(3):321-32.

5. Potts HW. Online support groups: an overlooked resource for patients. He@ Ith Information on the Internet. $2005 ; 44(1): 6-8$.

6. Sokol R, Fisher E. Peer support for the hardly reached: a systematic review. American journal of public health. 2016 Jul;106(7):e1-8.

7. Petosa RL, Smith LH. Peer mentoring for health behavior change: A systematic review. American Journal of Health Education. 2014 Nov 2;45(6):351-7.

8. Dale JR, Williams SM, Bowyer V. What is the effect of peer support on diabetes outcomes in adults? A systematic review. Diabetic Medicine. 2012 Nov;29(11):136177.

9. Bellamy, B., Schmutte, T., Davidson, L. An update on the growing evidence base for peer support. Mental Health and Social Inclusion Jun 2017; 21 (3): 61-67. ISSN: 2042 8308

10. Moore, S.E', McMullan, M', McEvoy, C.T', McKinley, M.C', Woodside, J.V. The effectiveness of peer-supported interventions for encouraging dietary behaviour change in adults: a systematic review. 328(7449):1166.

doi:10.1136/bmj.328.7449.1166

11. Patil, S.J., Ruppar, T., Koopman, R.J. et al. Effect of peer support interventions on cardiovascular disease risk factors in adults with diabetes: a systematic review and meta-analysis. BMC Public Health 18, 398 (2018) doi:10.1186/s12889-018-5326-8

12. Eysenbach G, Powell J, Englesakis M, Rizo C, Stern A. Health related virtual communities and electronic support groups: systematic review of the effects of online peer to peer interactions. BMJ. 2004; Public Health Nutr. 2019 Mar;22(4):624644. doi: 0.1017/S1368980018003294. Epub 2018 Dec 3. 
13. Department of Health. The Power of Information Putting all of us in control of the health and care information we need. 2009; Available from https://assets.publishing.service.gov.uk/government/uploads/system/uploads/attachm ent_data/file/213689/dh_134205.pdf Accessed 30/05/2019

14. Kayser L, Karnoe A, Furstrand D, et al. RHA Multidimensional tool based on the Health Literacy Framework: Development and initial validity testing of the eHealth Literacy Questionnaire (eHLQ) J Med Internet Res 2018;20(2):e36

15. Johnson MO. The Shifting Landscape of Health Care: Toward a Model of Health Care Empowerment Am J Public Health 2011; 101(2): 265-270

16. Age UK. 2019; Available from https://www.ageuk.org.uk/our-impact/programmes/onedigital/ Accessed 30/05/2019

17. Harding $\mathrm{C}$, Chung $\mathrm{H}$. Behavioral health support and online peer communities: international experiences. Mhealth. 2016;2.

18. Horvath KJ, Oakes JM, Rosser BS, Danilenko G, Vezina H, Amico KR, Williams ML, Simoni J. Feasibility, acceptability and preliminary efficacy of an online peer-to-peer social support ART adherence intervention. AIDS and Behavior. 2013 Jul $1 ; 17(6): 2031-44$

19. Fortuna KL, Brooks JM, Umucu E, Walker R, Chow PI. Peer support: A human factor to enhance engagement in digital health behavior change interventions. Journal of Technology in Behavioral Science. 2019:1-0.

20. Nanton V, Appleton R, Dale, J, et al. Integrated Care in Prostate Cancer (ICARE-P): Nonrandomized Controlled Feasibility Study of Online Holistic Needs Assessment, Linking the Patient and the Health Care Team. J Med Internet Res Prot 2017; 6 (7)e $147,1-10$

21. Clarke AL, Roscoe J, Appleton R, Parashar D, Muthuswamy R, Khan O, Dale J, Nanton 
V. Promoting integrated care in prostate cancer through online prostate cancerspecific holistic needs assessment: a feasibility study in primary care. Supportive Care in Cancer. 2019 Jul 23:1-1.

22. Clarke AL, Roscoe J, Appleton R, Dale J, Nanton V. “My gut feeling is we could do more..." a qualitative study exploring staff and patient perspectives before and after the implementation of an online prostate cancer-specific holistic needs assessment. BMC health services research. 2019 Dec;19(1):115.

23. NHS Jobs. 2019; Available from https://www.jobs.nhs.uk/xi/vacancy/? vac_ref $=915143003$ Accessed 30/05/2019

24. com Available from https://www.payscale.com/research/US/Job=Peer_Support_Specialist/Hourly_Rate Accessed 16/10/19

25. NHS England. Five Year Forward View. 2014; Available from https://www.england.nhs.uk/wpcontent/uploads/2014/10/5yfv-web.pdf Accessed $30 / 05 / 2019$

26. Goddard K. A different experience? Personal experience volunteers at a cancer charity. Voluntary Action London Institute For Volunteering Research. 2005;7(1):9.

27. Casiday R, Kinsman E, Fisher C, Bambra C. Volunteering and health: what impact does it really have. London: Volunteering England. 2008 Feb 3;9(3):1-3.

28. Lum TY, Lightfoot $\mathrm{E}$. The effects of volunteering on the physical and mental health of older people. Res Aging 2005;27(1):31-55

29. Dale J, Loew J, Nanton V, Smith GG. Coproduction of a Theory-Based Digital Resource for Unpaid Carers (The Care Companion): Mixed-Methods Study. JMIR Aging. $2018 ; 1(1): e 1$

30. NHS England. Recruiting and managing volunteers in NHS providers a practical guide. 
2017; Available from https://www.england.nhs.uk/wp-

content/uploads/2017/10/recruiting-managing-volunteers-nhs-providers-practicalguide.pdf Accessed 16/10/2019

31. NHS England. Digital Transformation. 2019; Available from https://www.england.nhs.uk/digitaltechnology/ Accessed 16/10/2019

32. Watts G. Why the exclusion of older people from clinical research must stop. Bmj. 2012 May 21;344:e3445. 